Pacific Journal of Mathematics

A METHOD OF APPROXIMATING THE COMPLEX ROOTS OF EQUATIONS 


\title{
A METHOD OF APPROXIMATING THE COMPLEX ROOTS OF EQUATIONS
}

\author{
STEPHEN KULIK
}

1. The method described in this paper presents an algorithm by which at least two roots of an equation can be approximated starting with the same first approximation. This is achieved by introducing a parameter and choosing its numerical value appropriately. In particular, in case of real roots, two adjacent or the largest and the smallest roots are approximated by the use of two different values of the parameter. This is discussed in $\S 3$. In case of conjugate imaginary roots the real and imaginary parts of the approximations are easily separated. This is discussed in $\S 4$.

2. Let $f(z)$ be an analytic function within and upon a circle $C$, and let the roots of the equation $f(z)=0$ within and upon the circle be denoted by $a_{j}, j=1,2, \cdots$, and their multiplicities by $m_{j}$ respectively.

We consider the expansion into the partial fractions of $(u-z)^{k} f^{\prime}(z) \mid f(z)$, where $k$ is a positive integer and $u \neq a$, or $z$ but otherwise arbitrary,

$$
(u-z)^{k} f^{\prime}(z) / f(z)=\sum_{j=1} m_{j}\left(u-a_{j}\right)^{k} /\left(z-a_{j}\right)+\phi_{1}(z),
$$

where $\psi_{1}(z)$ is analytic within and upon the circle, and the sum is taken over all the roots $a_{j}$ starting with $j=1$.

By differentiating (1) $n-1$ times and dividing by $(-1)^{n-1}(n-1)$ ! we derive

$$
Q_{n, k} /[f(z)]^{n}=\sum_{j=1} m_{j}\left(u-a_{j}\right)^{k} /\left(z-a_{j}\right)^{n}+\psi_{n}(z), \quad n \geqq k,
$$

where $\psi_{n}(z)$ is analytic within and upon $C$. The function $Q_{n, k} \equiv Q_{n, k}(z, u)$ can be evaluated by the formula

$$
Q_{n, k}=\sum_{j=0}^{n-1}\left(\begin{array}{c}
k \\
j
\end{array}\right)(u-z)^{k-j}[f(z)]^{j} D_{n-j}
$$

with $D_{n}$ evaluated recursively

$$
\begin{gathered}
D_{n}=\sum_{j=0}^{n-2} f^{(j+1)}(z)[-f(z)]^{\jmath} D_{n-j-1} /(j+1) !+f^{(n)}(z)[-f(z)]^{n-1} /(n-1) !, \\
\quad D_{0}=1, D_{1}=f^{\prime}(z)
\end{gathered}
$$

The function $Q_{n, k}$ can also be evaluated recursively, and both $Q_{n, k}$ and

Received November 14, 1957. Presented at the meeting of the American Mathematical Society at Pennsylvania State University, August 27-30, 1957. Sponsored by the OOR., U.S. Army, 1957. 
$D_{n}$ can be expressed in the form of determinants $[1,2]$.

We rewrite (2) as follows

$$
\begin{gathered}
Q_{n, k} /[f(z)]^{n}=m_{1}\left(u-a_{1}\right)^{k} /\left(z-a_{1}\right)^{n} \\
\times\left\{1+\left(z-a_{1}\right)^{n} / m_{1}\left(u-a_{1}\right)^{k}\left[\sum_{j=2} m_{j}\left(u-a_{j}\right)^{k} /\left(z-a_{j}\right)^{n}+\psi_{n}(z)\right]\right\},
\end{gathered}
$$

where the summation starts with $j=2$. Now, if we assume that $u$ and $z$ are given such values that

$$
\left|\left(u-a_{1}\right) /\left(z-a_{1}\right)\right|>\left|\left(u-a_{j}\right) /\left(z-a_{j}\right)\right|, \quad j=2,3, \cdots,
$$

and

$$
\left|\left(u-a_{1}\right) /\left(z-a_{1}\right)\right|>|(u-\zeta) /(z-\zeta)|,
$$

for any $\zeta$ on $C$, the following result follows :

$$
\left(u-a_{1}\right)^{c-b} /\left(z-a_{1}\right)^{a}=\lim _{n \rightarrow \infty} Q_{n, n-b} /[f(z)]^{a} Q_{n-a, n-c},
$$

where $a, b$, and $c$ are constants satisfying the conditions imposed on the subscripts of $Q_{n, k}$ in (2). An approximation to $a_{1}$ is obtained with a finite $n$.

Of particular practical value are the cases when the left hand side of the equation has only $u-a_{1}$, or $z-a_{1}$, or both of the first or second degree.

3. The reason for introducing the parameter $u$ into the problem is that more than one root can be approximated with the same $D_{1}, D_{2}$, $\cdots D_{n}$ by using different appropriately chosen values of $u$. This will be illustrated when the left hand side of (7) is either $u-a_{1},\left(u-a_{1}\right) /\left(z-a_{1}\right)$, or $1 /\left(z-a_{1}\right)$, namely :

$$
\begin{gathered}
\left(z-a_{1}\right) /\left(u-a_{1}\right)=\lim _{n \rightarrow \infty} f(z) Q_{n-1, n-1} / Q_{n, n} \\
z-a_{1}=\lim _{n \rightarrow \infty} f(z) Q_{n-1, n-1} / Q_{n, n-1} \\
u-a_{1}=\lim _{n \rightarrow \infty} Q_{n, n} / Q_{n, n-1} \\
\left(z-a_{1}\right) /\left(u-a_{1}\right)=\lim _{n \rightarrow \infty} f(z) Q_{n-1, n-2} / Q_{n, n-1}
\end{gathered}
$$

Let us assume that $z=x$ is real and that the two roots closest to $x$ are also real, $a_{1}<x<a_{2}, x-a_{1}<a_{2}-x$. Then, as it can easily be verified, an approximation to $a_{1}$ can be obtained with any $u_{1}>x$, and $\infty<u_{1}<\left[\left(a_{1}+a_{2}\right) x-2 a_{1} a_{2}\right] /\left(2 x-a_{1}-a_{2}\right)$; an approximation to $a_{2}$ can be obtained with any $\left[\left(a_{1}+a_{2}\right) x-2 a_{1} a_{2}\right] /\left(2 x-a_{1}-a_{2}\right)<u_{2}<x$ (Diagram 1$)$. The 
above inequalities defining $u_{1}$ and $u_{2}$ should also be used when $a_{1}<x$ is the largest real root of an equation and $a_{2}$ the smallest (Diagram 2).

Before applying any of (8)-(11), an approximation to $a_{1}$ can be obtained by using a more particular case of $(7)[1,2]$ :

$$
z-a_{1}=\lim _{n \rightarrow \infty} f(z) D_{n-1} / D_{n}=\lim _{n \rightarrow \infty}\left[f^{(n)}(z) D_{n}\right]^{1 / n}
$$

This gives an idea as to the location of the root closest to $x$.

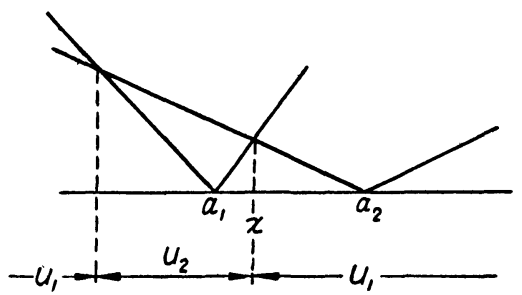

Diagram 1

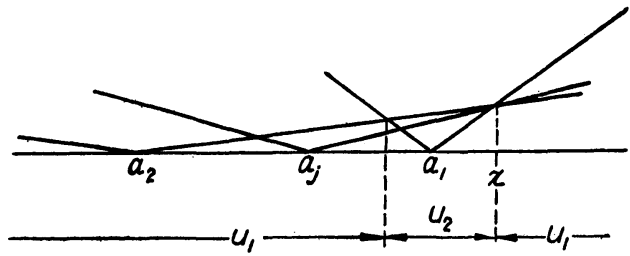

Diagram 2

4. Let now $z=x$ be real equidistant from two conjugate imaginary roots $a+b i$ and $a-b i$. Then $u$ can be taken in the form $x+t i$ and the real and imaginary parts in the equations (8)-(11) can easily be separated. In this case, if $x$ is closer to $a+b i$ and $a-b i$ than to any other root of the equation, and if the equation has no more imaginary roots, any positive $t$ can be taken to approximate $a-b i$ (Diagram 3 ). If the equation has another imaginary root not much more distant from $x$ than $a-b i$, and with real part closer to $x$ than $a$, a large value of $t$ would be required (Diagram 4). The imaginary root $a-b i$ can be approximated with some positive $t$ (Diagram 5) even if there is a real root which is closer to $x$ than to $a-b i$, but not very close, and if the real part, $a$, is close to $x$.

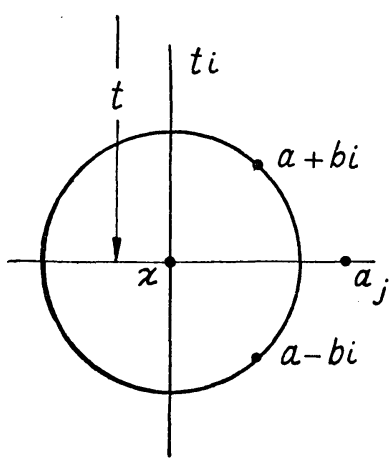

Diagram 3

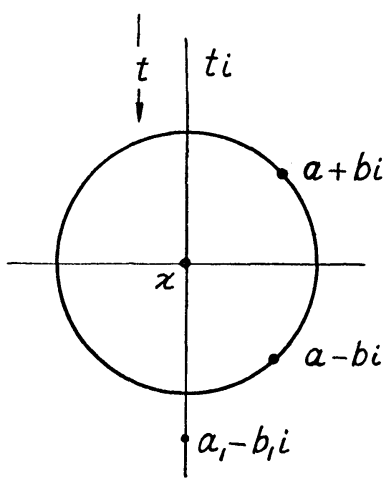

Diagram 4

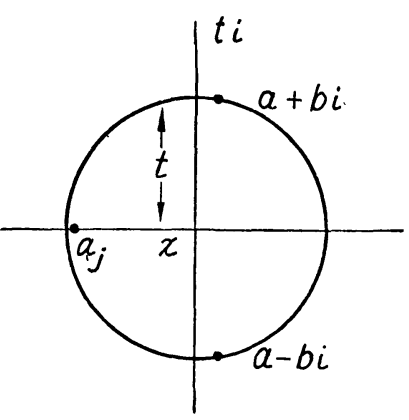

Diagram 5

We shall now give the explicit formulas for the real and imaginary 
parts of a root $a_{1}$ in the four cases given by (8)-(11).

We designate $z=x+t i$, as before, where $x$ and $t$ are real, $t>0$, $a_{1}=a-b i, Q_{n, n}=A_{n, n}+i B_{n, n}, Q_{n, n-1}=A_{n, n-1}+i B_{n, n-1}$, where

$$
\begin{gathered}
A_{n, n}=-t^{2} \sum_{j=1}(-1)^{j-1}\left(\begin{array}{c}
n \\
2 j
\end{array}\right) t^{2 j-2}[f(x)]^{n-2 j} D_{2 j}, \\
B_{n, n}=t \sum_{j=1}(-1)^{j-1}\left(\begin{array}{c}
n \\
2 j-1
\end{array}\right) t^{2 j-2}[f(x)]^{n-2 j+1} D_{2 j-1} ; \\
A_{n, n-1}=\sum_{j=1}(-1)^{j-1}\left(2 j^{n-1}-2\right) t^{2 j-2}[f(x)]^{n-2 j+1} D_{2 j-1}, \\
B_{n, n-1}=t \sum_{j=1}(-1)^{j-1}\left(2 j^{n-1}-1\right) t^{2 j-2}[f(x)]^{n-2 j} D_{2 j} .
\end{gathered}
$$

The sums being taken over all $j$, for which the binomial coefficients do not vanish, starting with $j=1$.

Now by using (8)-(11) we get respectively

$$
\begin{gathered}
x-a=\lim _{n \rightarrow \infty} t f(x)\left[B_{n-1, n-1}\left(f(x) A_{n-1, n-1}-A_{n, n}\right)\right. \\
\left.-A_{n-1, n-1}\left(f(x) B_{n-1, n-1}-B_{n, n}\right)\right] / \Delta, \\
b=-\lim _{n \rightarrow \infty} t f(x)\left[A_{n-1, n-1}\left(f(x) A_{n-1, n-1}-A_{n, n}\right)\right. \\
\left.-B_{n-1, n-1}\left(f(x) B_{n-1, n-1}-B_{n, n}\right)\right] / \Delta,
\end{gathered}
$$

where

$$
\begin{gathered}
\Delta=\left[f(x) A_{n-1, n-1}-A_{n, n}\right]^{2}+\left[f(x) B_{n-1, n-1}-\mathrm{B}_{n, n}\right]^{2} ; \\
x-a=\lim _{n \rightarrow \infty} f(x)\left(A_{n, n-1} A_{n-1, n-1}+B_{n, n-1} B_{n-1, n-1}\right) /\left(A_{n, n-1}^{2}+B_{n, n-1}^{2}\right), \\
b=\lim _{n \rightarrow \infty} f(x)\left(A_{n, n-1} B_{n-1, n-1}-B_{n, n-1} A_{n-1, n-1}\right) /\left(A_{n, n-1}^{2}+B_{n, n-1}^{2}\right) ; \\
x-a=\lim _{n \rightarrow \infty}\left(A_{n, n} A_{n, n-1}+B_{n, n} B_{n, n-1}\right) /\left(A_{n, n-1}^{2}+B_{n, n-1}^{2}\right), \\
t-b=\lim _{n \rightarrow \infty}\left(A_{n, n} B_{n, n-1}-B_{n, n} A_{n, n-1}\right) /\left(A_{n, n-1}^{2}+B_{n, n-1}^{2}\right) ; \\
x-a=\lim _{n \rightarrow \infty} t f(x)\left[B_{n-1, n-2}\left(f(x) A_{n-1, n-2}-A_{n, n-1}\right)\right. \\
\left.-A_{n-1, n-2}\left(f(x) B_{n-1, n-2}-B_{n, n-1}\right)\right] / \Delta_{1}, \\
b=\lim _{n \rightarrow \infty} t f(x)\left[A_{n-1, n-2}\left(f(x) A_{n \cdot 1, n-2}-A_{n, n-1}\right)\right. \\
\quad-B_{n-1, n-2}\left(f(x) B_{n-1, n-2}-B_{n, n-1}\right) / \Delta_{1},
\end{gathered}
$$

where

$$
\Delta_{1}=\left[f(x) A_{n-1, n-2}-A_{n, n-1}\right]^{2}+\left[f(x) B_{n-1, n-2}-B_{n, n-1}\right]^{2} .
$$

5. Results analogous to those presented above can be obtained by considering other expansions similar to those given by (2). We mention 
here one such result assuming that $f(z)$ has only simple zeros. We consider then $(u-z)^{k} / f(z)$ instead of $(u-z)^{k} f^{\prime}(z) / f(z)$ and derive the equation

$$
Q_{n, k}^{1} /[f(z)]^{n}=\sum_{j=1} A_{j}\left(u-a_{j}\right)^{k} /\left(z-a_{j}\right)^{n}+\psi_{n}^{1}(z)
$$

where $A_{j}$ are constants.

$$
\begin{aligned}
& Q_{n, k}^{1}=\sum_{j=0}^{n-1}\left(\begin{array}{l}
k \\
j
\end{array}\right)(u-z)^{k-j}[f(z)]^{j} P_{n-j-1} \\
& P_{n}=\sum_{j=0}^{n-1} f(z)^{(j+1)}[-f(z)]^{\jmath} P_{n-j-1}, \\
& P_{0}=1 \text {. }
\end{aligned}
$$

It would suffice now to replace $Q_{n, k}$ by $\mathrm{Q}_{n k}^{1}$ in all the previous formulas.

6. If $f(z)$ is a polynomial of degree $N$ and $k=n$, then the last member on the right hand side of (2) equals $-N$. If taken to the left hand side, it would contribute the term $N[f(z)]^{n}$ to $Q_{n, n}$, consequently, $N[f(z)]^{n}$ and $N[f(z)]^{n-1}$ will be contributed to $A_{n, n}$ and $A_{n-1, n-1}$ respectively in (8), (9), and (10). In case of equation (19), however, the last member would be reduced to $-A_{1}-A_{2}-\cdots-A_{N}$.

\section{REFERENCES}

1. S. Kulik, A new method for evaluating the zeros of analytic functions, Interim Technical Report No. 1, OOR., U.S, Army, 1956.

2. - A method for approximating the zeros of analytic functions, Duke Math. J. 24, (1957), 137-142.

University of SOUth Carolina 



\section{PACIFIC JOURNAL OF MATHEMATICS}

\section{EDITORS}

\section{H. L. Royden}

Stanford University

Stanford, California

\section{R. A. Beaumont}

University of Washington

Seattle 5 , Washington

\author{
A. L. Whiteman
}

University of Southern California

Los Angeles 7, California

E. G. Straus

University of California

Los Angeles 24, California

\section{ASSOCIATE EDITORS}
E. F. BECKENBACH
A. HORN
L. NACHBIN
G. SZEKERES
C. E. BURGESS
V. GANAPATHY IYER
I. NIVEN
F. WOLF
M. HALL
R. D. JAMES
T. G. OSTROM
E. HEWITT
M. S. KNEBELMAN
M. M. SCHIFFER
K. YOSIDA

\section{SUPPORTING INSTITUTIONS}

\author{
UNIVERSITY OF BRITISH COLUMBIA \\ CALIFORNIA INSTITUTE OF TECHNOLOGY \\ UNIVERSITY OF CALIFORNIA \\ MONTANA STATE UNIVERSITY \\ UNIVERSITY OF NEVADA \\ OREGON STATE COLLEGE \\ UNIVERSITY OF OREGON \\ UNIVERSITY OF SOUTHERN CALIFORNIA
}

\author{
STANFORD UNIVERSITY \\ UNIVERSITY OF UTAH \\ WASHINGTON STATE COLLEGE \\ UNIVERSITY OF WASHINGTON \\ * * * * \\ AMERICAN MATHEMATICAL SOCIETY \\ CALIFORNIA RESEARCH CORPORATION \\ HUGHES AIRCRAFT COMPANY \\ THE RAMO-WOOLDRIDGE CORPORATION
}

Mathematical papers intended for publication in the Pacific Journal of Mathematics should be typewritten (double spaced), and the author should keep a complete copy. Manuscripts may be sent to any of the editors. All other communications to the editors should be addressed to the managing editor, E. G. Straus at the University of California, Los Angeles 24, California.

50 reprints per author of each article are furnished free of charge; additional copies may be obtained at cost in multiples of 50 .

The Pacific Journal of Mathematics is published quarterly, in March, June, September, and December. The price per volume (4 numbers) is $\$ 12.00$; single issues, $\$ 3.50$. Back numbers are available. Special price to individual faculty members of supporting institutions and to individual members of the American Mathematical Society: $\$ 4.00$ per volume; single issues, $\$ 1.25$.

Subscriptions, orders for back numbers, and changes of address should be sent to Pacific Journal of Mathematics, 2120 Oxford Street, Berkeley 4, California.

Printed at Kokusai Bunken Insatsusha (International Academic Printing Co., I.td.), No. 10, 1-chome, Fujimi-cho, Chiyoda-ku, Tokyo, Japan.

PUBLISHED BY PACIFIC JOURNAL OF MATHEMATICS, A NON-PROFIT CORPORATION

The Supporting Institutions listed above contribute to the cost of publication of this Journal, but they are not owners or publishers and have no responsibility for its content or policies. 


\section{Pacific Journal of Mathematics}

\section{Vol. 8, No. 2 \\ April, 1958}

John Herbert Barrett, Second order complex differential equations with a real independent variable ............................ 187

Avner Friedman, Remarks on the maximum principle for parabolic equations and its applications ......................... 201

Richard Robinson Goldberg, An inversion of the Stieltjes transform ....... 213

Olavi Hellman, On the periodicity of the solution of a certain nonlinear integral equation .................................. 219

Gilbert Helmberg, A theorem on equidistribution on compact groups...... 227

Lloyd Kenneth Jackson, Subfunctions and the Dirichlet problem ......... 243

Naoki Kimura, The structure of idempotent semigroups. I ............ 257

Stephen Kulik, A method of approximating the complex roots of equations........................................ 277

Ancel Clyde Mewborn, A note on a paper of L. Guttman.............. 283

Zeev Nehari, On the principal frequency of a membrane ............ 285

G. Pólya and I. J. Schoenberg, Remarks on de la Vallée Poussin means and convex conformal maps of the circle ...................... 295

B. M. Stewart, Asymmetry of a plane convex set with respect to its centroid .......................................... 335

Hans F. Weinberger, Lower bounds for higher eigenvalues by finite difference methods

Edwin Weiss and Neal Zierler, Locally compact division rings ......... 369

Bertram Yood, Homomorphisms on normed algebras ................. 373 